\title{
Construção de um mapa climático analítico para a cidade de Belo Horizonte, Brasil
}

\section{Building an urban climatic analysis map for Belo Horizonte city, Brazil}

Daniele Gomes Ferreira ${ }^{[a]}$, Eleonora Sad de Assis ${ }^{[0]}$, Lutz Katzschner ${ }^{[b]}$

[a] Universidade Federal de Minas Gerais (UFMG), MG, Brasil

[b] Universidade de Kassel, Alemanha

\section{Resumo}

O artigo propõe a adaptação e aplicação da metodologia alemã de construção de mapas climáticos aplicando conceitos de climatopos para a cidade de Belo Horizonte. Foram analisados dados de uso do solo, aspectos geográficos e informações sobre os ventos, formando diferentes camadas de mapas temáticos. A combinação das camadas possibilitou a definição de oito classes de climatopos, conformando um mapa climático urbano analítico. Verificou-se que áreas da cidade, localizadas nos extremos sul, sudeste e nordeste do município e que concentram as maiores extensões de áreas verdes, têm maior potencial dinâmico e menor carga térmica, o que favorece o resfriamento noturno. As áreas densamente ocupadas e que correspondem ao centro da cidade, por sua vez, têm baixa capacidade de resfriamento noturno, pois a carga térmica acumulada e o baixo potencial dinâmico favorecem o aquecimento das superfícies. Quanto à distribuição das classes de climatopos, observou-se que cerca da metade do território da cidade apresenta como resposta atmosférica carga térmica negativa e bom potencial dinâmico, o que indica que o impacto negativo dos elementos urbanos na carga térmica superficial pode ser considerado ainda baixo. Os resultados obtidos são a base para a formulação de recomendações para o planejamento urbano de Belo Horizonte, que tem como princípio a preservação e a ampliação de áreas urbanas que possam contribuir para a melhoria do clima local.

Palavras-chave: Mapa climático urbano. Clima urbano. Planejamento urbano.

DGF é Arquiteta e Urbanista, Doutoranda, e-mail: dani.gferreira@yahoo.com.br ESA é Arquiteta e Urbanista, Doutora, e-mail: eleonorasad@yahoo.com.br LK é Meteorologista e Professor, Doutor, e-mail: katzschn@uni-kassel.de 


\section{Abstract}

The article proposes the adaptation and application of the German methodology for the construction of climatic maps for the city of Belo Horizonte. Land use data, geographic aspects and wind information were analyzed, producing different layers of thematic maps. Their combination allowed a definition of eight classes of climatopes, making an analytical urban climatic map. It was verified that the edges of the city at south, southeast and northeast, which the green areas are concentrated, have greater dynamic potential and lower thermal load, considered an advantage for nocturnal cooling. However, the densely built-up areas located in the city center have low nocturnal cooling capacity, due to thermal load storage and the lowest dynamic potential that favor the heating of the surfaces. Concerning to the distribution of climatope classes, it was observed that about half of the city area presents a negative thermal load and a good dynamic potential as an atmospheric response. This result indicates that the negative impact of the urban elements on the surface thermal load can be considered still low. The results are also the basis for urban planning recommendations in order to preserve and expand urban areas that can contribute to the improvement of the local climate of Belo Horizonte.

Keywords: Urban climatic map. Urban climate. Urban planning.

\section{Introdução}

0 processo de urbanização altera o comportamento das variáveis climáticas em âmbito local, produzindo condições atmosféricas que definem o clima urbano. Com o aumento da população em áreas urbanas, os efeitos deste processo são sentidos de forma cada vez mais intensa, criando problemas ambientais associados à deterioração ambiental, tais como a poluição do ar, ilhas de calor e episódios de chuvas concentradas. De acordo com Aylett (2015) as iniciativas para responder a estes problemas urbanos ainda ocorrem majoritariamente em escalas locais, não havendo uma resposta internacional coordenada para as alterações climáticas provocadas pelas cidades.

As características do clima urbano típico dependem não somente do tamanho da cidade, mas também são influenciadas pelo relevo, pela morfologia urbana, pelos tipos de superfícies, pela proporção de espaços abertos, etc. Enquanto alguns fatores atmosféricos, como a luz solar, apresentam pouca variação em relação ao território da cidade, outras variáveis, como a temperatura do ar e os padrões de vento, apresentam variação espacial substancial, pois são influenciadas por fatores como a capacidade das edificações de acumular calor, o tipo de cobertura do solo e a presença de corpos d'água. Pequenas variações espaciais, por sua vez, podem ser encontradas em áreas de edificações, ruas e espaços verdes (Planning Department of Hong Kong, 2006).
O conhecimento do comportamento das variáveis climáticas nas áreas urbanas é fundamental na mitigação dos efeitos adversos da urbanização. Taesler (1986) e Mills (2015) apontam que muitos dos problemas ambientais poderiam ser reduzidos se o planejamento urbano incorporasse estudos relativos ao clima. Porém, há uma dificuldade na tradução dos estudos de climatologia urbana para a linguagem do planejamento. De fato, observa-se que a trajetória para tal integração tem sido longa e dependente de uma base consistente de dados medidos localmente.

Pode-se dizer que a linha principal de investigação internacional sobre o clima urbano e suas repercussões sobre o planejamento das cidades se desenvolveu tendo por base a modelagem climática convencional, a partir das abordagens da geografia e meteorologia. Na medida do avanço de recursos computacionais e das bases de dados medidos na última metade do século $\mathrm{XX}$, os modelos, fundamentalmente numéricos, puderam chegar a melhores resoluções espaciais, sendo, assim, capazes de considerar mais detalhadamente a superfície e, portanto, alguns aspectos das superfícies urbanas (Assis, 2005).

Tais avanços, entretanto, não têm sido suficientes para integrar o conhecimento da climatologia urbana ao planejamento, pois ainda carecem de capacidade preditiva, segundo a crítica de renomados pesquisadores na área, como Oke (1984) e Monteiro (1986). Mais do que isso, contudo, Assis 
(2005) aponta que a falta de referencial humano nesta linha, além do foco essencialmente descritivo, tem sido uma barreira para a compreensão dos resultados e sua incorporação no planejamento e desenho urbanos.

Nesse sentido, a abordagem que se desenvolveu principalmente na Alemanha, a partir dos anos 1970, curiosamente muito próxima da visão teórica do clima urbano proposta por Monteiro (1976), considera a elaboração dos dados e informações a partir de canais de percepção humana, como conforto térmico e qualidade do ar. Tal abordagem pôde suprir mais rápida e adequadamente a necessidade de informação formatada para a tomada de decisão em planejamento urbano.

De fato, os primeiros estudos realizados com a perspectiva de associar o clima ao planejamento urbano ocorreram na Europa, na década de 1970, geralmente a partir da constatação das más condições de qualidade do ar urbano. Na Áustria, a cidade de Graz desenvolveu, em 1974, um programa de tráfego associado ao controle da poluição atmosférica. Entretanto, somente em 1990 uma base de dados consistente, representada em forma de mapas, serviu como apoio para a lei de uso e plano de desenvolvimento urbano (Lazar \& Podesser, 1999).

A cidade de Stuttgart, no sul da Alemanha, conta com um Departamento de Climatologia Urbana desde 1938. Em 1977, já desenvolvia com maturidade metodológica este tipo de planejamento integrado, buscando controlar problemas de poluição do ar e das más condições de ventilação resultantes do bloqueio das edificações às correntes principais de vento (Lazar \& Podesser, 1999). Medições sistemáticas foram realizadas, através de estações fixas, pelo Departamento de Climatologia Urbana desta cidade até 1982, quando um veículo foi equipado para fazer medições móveis em vários pontos da área urbana, caracterizando melhor condições microclimáticas variadas. Posteriormente a este estudo, o governo do estado de Baden-Württemberg, onde se localiza Stuttgart, produziu uma cartilha com diretrizes para a consideração do clima no zoneamento e planejamento urbanos (Baden-Württemberg Innenministerium, 2004), apresentando procedimentos para a análise de variáveis climáticas e sua inserção nas práticas de planejamento.

Em Lisboa, Portugal, as investigações para aplicação da climatologia ao planejamento tiveram início na década de 1980, através do projeto CLIMLIS $^{1}$ e se concretizaram, em 2005, com um relatório de orientações climáticas para o planejamento e ordenamento urbanos (Alcoforado et al., 2006). Este trabalho apresenta a caracterização geral do clima da cidade, a partir da análise de dados de estações meteorológicas, mostrando a influência das estações do ano na variação das condições climáticas médias.

De acordo com Ren et al. (2011), o desenvolvimento da experiência dessas e outras cidades europeias, principalmente no caso da Alemanha, levou à articulação de uma plataforma de informação para comunicação e colaboração interdisciplinar. 0 chamado mapa climático urbano (urban climatic map - UCMap) pode ser visto dentro de tal contexto. Ele é uma ferramenta de informação e análise que integra considerações sobre fatores climáticos e planejamento urbano, representadas cartograficamente, e que podem ser avaliadas e aplicadas no planejamento com o auxílio de mapas de referência (VDI, 1997). O UCMap é composto por dois componentes principais (Ren et al., 2011): o mapa climático urbano analítico (urban climatic analysis map - UCAnMap), que é um mapa sintético de funções climáticas, e o mapa climático de recomendações para o planejamento (urban climatic planning recommendation map - UC-ReMap).

A metodologia é quali/quantitativa, derivada da consolidação da experiência alemã que, a partir dos anos 1990, começou a produzir normas técnicas sobre o assunto. Baseia-se na avaliação concomitante do uso do solo e de aspectos geográficos (topografia e dados meteorológicos), utilizando um sistema de informação geográfica (SIG). Tanto Alcoforado et al. (2006) como Katzschner (2005) utilizam o conceito de climatopo ${ }^{2}$, definido por Scherer et al. (1999) como áreas geográficas com características microclimáticas similares, que atuam em seu entorno de forma análoga e podem atingir escalas espaciais que variam de dezenas a centenas de metros; também entendido como unidades de resposta atmosférica (atmospheric response units). Os dados de temperatura, umidade, direção e velocidade dos ventos são

\footnotetext{
1 Projeto denominado "Princípios climáticos para o planeamento urbano. Aplicação a Lisboa”.

2 Os trabalhos de Katzschner \& Mulder (2008), Katzschner (1997) e Katzschner (2005), apesar de não utilizarem a nomenclatura "climatopo", usam uma metodologia que reconhece áreas homogêneas quanto ao clima.
} 
provenientes de estações meteorológicas próximas à área de estudo e/ou de dados medidos em campo. Estes dados são cruzados, classificados e transformados em mapas de funções climáticas urbanas, os quais são baseados em princípios físicos que caracterizam o balanço de energia do clima urbano (carga térmica e potencial dinâmico ${ }^{3}$, principalmente). A partir de análises dos resultados do mapa de funções climáticas são formuladas as diretrizes de planejamento, que são representadas em mapas de recomendações.

Segundo Ren et al. (2011), cidades de mais de 15 países já desenvolveram seus mapas climáticos analíticos, utilizando medições climáticas e propondo recomendações para a prática do planejamento urbano local. A maioria destes países estão na Europa e, em menor proporção, na Ásia (China, Japão e Tailândia). Na Ásia, a metodologia já foi aplicada a sete vilas na China (Katzschner \& Mülder, 2008) e na cidade de Hong Kong. Os mapas foram elaborados com o intuito de atualizar as normas de planejamento, as quais contém diretrizes específicas de desenho urbano baseadas na condição e no acesso à ventilação (Planning Department of Hong Kong, 2006). Por sua vez, a cidade de Tóquio, no Japão, vem implementando medidas, desde 2002, para combater efeitos da ilha de calor urbana, o que resultou no seu Mapa do Ambiente Térmico em 2005 e em recomendações de planejamento e desenho urbanos para a mitigação da ilha de calor. Neste caso, a metodologia não foi totalmente aplicada, não havendo a consideração do potencial dinâmico (ventilação) para a melhoria das condições climáticas da cidade (Planning Department of Hong Kong, 2006).

Na América do Sul os trabalhos são ainda escassos. Em 2005, Katzschner apresentou no Brasil uma metodologia para avaliação das condições climáticas através de áreas homogêneas, para fins de planejamento urbano. A cidade de Salvador (BA) foi pioneira na aplicação desta metodologia (Nery et al., 2006). Souza (2010) desenvolveu um mapa climático utilizando ferramentas do tipo SIG para

\footnotetext{
3 O parâmetro carga térmica representa o armazenamento de calor pelas estruturas urbanas, em especial do volume edificado das construções, mas depende também da topografia e da disponibilidade de áreas verdes. 0 potencial dinâmico, por sua vez, avalia a rugosidade do solo e, consequentemente, a disponibilidade de ventos, as trocas de massa de ar frio em áreas de terreno natural em encostas e a proximidade de áreas abertas (Planning Department of Hong Kong, 2006).
}

a cidade de João Pessoa (PB). Prata-Shimomura et al. (2015) desenvolveram um mapa climático para a cidade de Campinas a partir de estudos de vento e definindo os climatopos para o município, contudo, ainda não há implementação no planejamento urbano municipal. Assim, apesar do esforço realizado nestas pesquisas, as cidades brasileiras ainda não incorporaram recomendações climáticas em suas legislações urbanísticas.

A pouca ênfase nos estudos urbanos associados ao clima e sua aplicação no planejamento urbano no mundo pode ser um reflexo de como a questão das mudanças climáticas é abordada pelas estruturas institucionais de governo. De acordo com pesquisa realizada por Aylett (2015) com mais de 300 municipalidades em todos os continentes, verifica-se que a maioria das equipes de planejamento climático está localizada em agências ambientais, o que, do ponto de vista das estruturas institucionais, é uma posição marginal e com menos recursos e jurisdição nos governos locais. Neste sentido, é preciso fortalecer pesquisas neste âmbito e procurar a sua implementação em políticas públicas que, no caso dos mapeamentos climáticos, estão associadas diretamente ao planejamento urbano.

Diante desse contexto, e reconhecendo a lacuna de estudos sobre clima urbano aplicados ao planejamento no Brasil, é que se buscou desenvolver um mapa climático analítico para a cidade de Belo Horizonte, MG.

\section{Caso de estudo: a cidade de Belo Horizonte}

Belo Horizonte é uma cidade planejada e construída há pouco mais de um século - foi inaugurada em 1897 - para ser a capital do estado de Minas Gerais. Foi projetada como um símbolo da modernidade do Brasil republicano, dentro de princípios positivistas oriundos dos médicos e engenheiros sanitaristas que compuseram a Comissão Construtora e de uma perspectiva progressista baseada no modelo urbanístico europeu, notadamente o francês (Assis, 1995). Tendo sido desenhada originalmente para 200.000 habitantes, levando em conta as condições de vento e as temperaturas amenas da região, com parques urbanos, avenidas boulevares e praças ajardinadas dentro de seu perímetro urbano à época (a avenida do Contorno), Belo Horizonte 
é um bom exemplo para se observar a eficácia dos conceitos e considerações ambientais nesses primórdios do urbanismo, assim como os efeitos da falta posterior de planejamento, do crescimento acelerado e das políticas urbanas ao longo de seu desenvolvimento.

Assim, apesar do planejamento inicial e de possuir legislação urbanística desde 1930, quando a cidade passou a crescer aceleradamente, são perceptíveis atualmente mudanças climáticas locais, principalmente em termos de temperatura e velocidade dos ventos, decorrentes da urbanização (Assis \& Abreu, 2009; Ferreira, 2009).

Belo Horizonte localiza-se na região centro-sul do estado, sendo uma das dez cidades mais populosas do Brasil, com densidade demográfica de cerca de 7.000 habitantes $/ \mathrm{km}^{2}$ (baseado em dados populacionais de 2010, IBGE). 0 município compreende uma área de $330,9 \mathrm{~km}^{2}$, com relevo movimentado formado por colinas com declividades variadas, com altitudes que vão de $650 \mathrm{~m}$, na porção nordeste do município, a mais de $1.150 \mathrm{~m}$, na Serra do Curral, nos seus limites sul e sudeste. 0 clima da região onde está situada pode ser classificado como tropical de altitude, com temperatura e umidade relativa médias anuais de $21,1^{\circ} \mathrm{C}$ e $72,2 \%$, respectivamente, e vento predominante leste com velocidade média anual de 1,4 m/s (INMET, 2009). Porém, a variabilidade altimétrica de formas do relevo e da própria ocupação urbana são responsáveis por gerar certa complexidade nas escalas topo e microclimáticas. A Figura 1 mostra as principais classes de uso do solo do município.

Desde a Lei de Uso e Ocupação do Solo (LUOS) municipal de 1996, todo o território do município é considerado zona urbana (Arts. 4을 e $5^{\circ}$ da Lei n. 7.166, de 27 de agosto de 1996). Esta Lei, ainda vigente ${ }^{4}$, divide o município nas seguintes zonas: Zona de Preservação Ambiental (ZPAM), Zona de Proteção (ZP), Zona de Adensamento Restrito (ZAR), Zona de Adensamento Preferencial (ZAP), Zona Central (ZC), Zona Adensada (ZA), Zona de Especial Interesse Social (ZEIS) e Zona de Grandes Equipamentos (ZE). As zonas ZC e ZAP são as que apresentam os maiores valores de coeficiente de aproveitamento no município, sendo, portanto, áreas mais suscetíveis à verticalização e ao adensamento urbano. As ZAs também têm alto coeficiente de aproveitamento, contudo são áreas em que o adensamento deve ser contido.

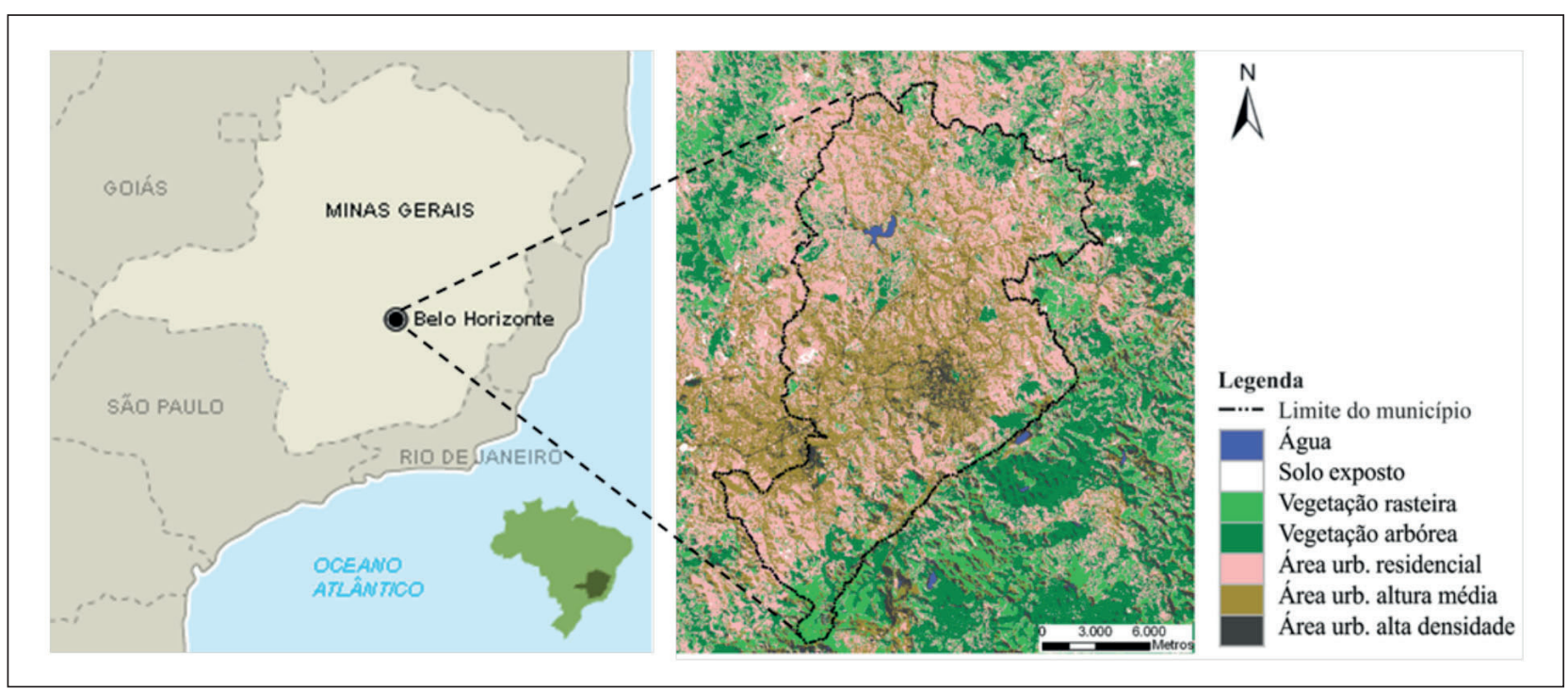

Figura 1- Localização do município de Belo Horizonte e suas principais classes de uso do solo.

Fonte: Base cartográfica do limite do município definido em 2001 pelo IGA/MG e atualizado, em 2005, pela Prodabel/PBH. Classificação do uso do solo realizada por Ferreira (2009).

\footnotetext{
${ }^{4}$ A revisão da LUOS-1996, através da Lei 9.959, de 20 de julho de 2010, não alterou o zoneamento do município, tendo tratado, mais especificamente, das normas e condições de urbanização das áreas de especial interesse social (ZEIS).
} 
Apesar do avanço inicial com relação a outras capitais do país, a primeira lei que efetivamente regulamentou o uso e a ocupação do solo urbano municipal foi aprovada somente na década de 1970 (Lei n. 2.662, de 29 de novembro de 1976). Naquele momento, contudo, já a maior parte do município estava ocupada, como mostra a Figura 2. Restavam poucas áreas livres, concentradas principalmente ao longo da Serra do Curral e a nordeste. Ainda hoje, estas regiões possuem as maiores áreas verdes da cidade, sendo que, no limite sudeste, a presença de unidades de conservação municipais e estaduais (áreas classificadas como vegetação rasteira e arbórea na Figura 1) garantem a não ocupação do local.

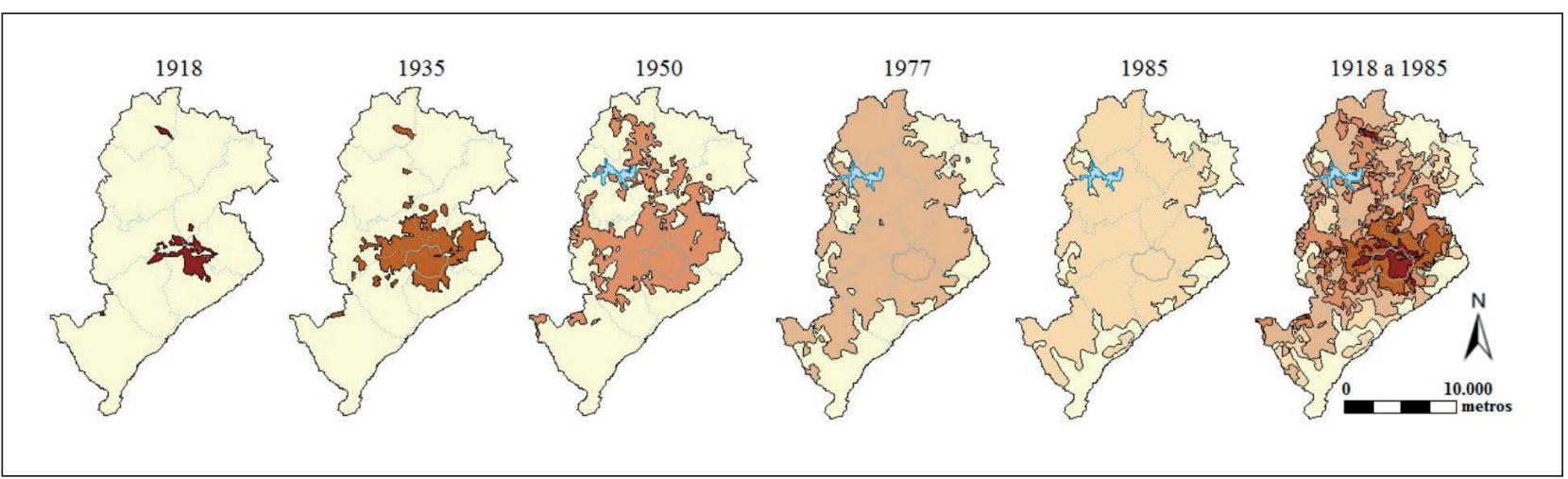

Figura 2 - Evolução da mancha urbana de Belo Horizonte, período 1918 a 1995.

Fonte: Adaptado de Amaral, s/d.

Alguns estudos apontam o efeito da urbanização na alteração das condições do clima local. Assis (2010), em uma perspectiva temporal de análise de elementos climáticos, observou que, de modo geral, em cerca de um século da existência da cidade (1911 a 2009) foi possível verificar mudanças nas variáveis climáticas, que apontaram para um ligeiro aquecimento da atmosfera local e uma redução da umidade. Ferreira (2009), por sua vez, verificou que, no período entre 1986 e 2006, o aumento da verticalização e o adensamento do tecido urbano provocaram alterações na velocidade do vento, reduzindo sua magnitude na maior parte do território da cidade. Em estudo comparativo que avaliou a condição dos ventos em Belo Horizonte e o zoneamento urbanístico, Ferreira e Assis (2015) observaram também que muitos locais onde o adensamento e a verticalização são permitidos e/ou incentivados correspondem a regiões em que a velocidade dos ventos é naturalmente baixa, concluindo que a lei de uso e ocupação do solo em vigor (a já citada Lei n. 7.166, de 27 de agosto de 1996) contribui para que as condições de ventilação na cidade possam ser cada vez mais prejudicadas. As áreas classificadas como
ZAP, ZA e ZC, onde o adensamento urbano seria permitido, corresponderam a regiões com condições de ventilação já prejudicadas em função de barreiras do relevo.

\section{Métodos e técnicas}

A construção do mapa climático urbano para Belo Horizonte foi baseada, portanto, na metodologia de climatopos. 0 princípio que norteia esta construção é o método de análise multicritério, aplicado à análise espacial, com o objetivo de construir um modelo descritivo do território. A principal função deste método é facilitar a integração de variáveis espaciais, as quais são representadas sob a forma de mapas temáticos (Moura et al., 2014).

Para o reconhecimento, no território, das áreas geográficas com características microclimáticas similares e que atuam em seu entorno de forma análoga (áreas representadas pelos climatopos), foram avaliados de forma concomitante dados de uso do solo, aspectos geográficos e informações sobre a velocidade dos ventos. A partir deste 
conjunto de dados, que representam diferentes camadas de mapas, foram atribuídos empiricamente pesos a cada variável, porém considerando os princípios conhecidos e as relações destas variáveis dentro do sistema clima urbano.

Utilizando a ferramenta de álgebra de mapas, executada no programa $\mathrm{ArcGis}^{\oplus}$ que permite a combinação dos diferentes mapas temáticos, foi possível definir áreas com características climáticas homogêneas. Tais áreas foram agrupadas em classes de climatopos, que agregam informações sobre a carga térmica e o potencial dinâmico para cada um, conformando assim, um mapa climático urbano analítico para Belo Horizonte. A seguir será detalhada a metodologia utilizada.

\section{Camadas de mapas e sua classificação}

Para a análise das condições microclimáticas locais, há que se considerar os elementos do balanço de energia da superfície urbana que contribuem para efeitos positivos ou negativos que, respectivamente, reduzem ou aumentam, a carga térmica no nível urbano. Ao mesmo tempo é importante avaliar o potencial dinâmico local que, por sua vez, contribui para a redução da carga térmica.

Assim, cada camada de mapa representa uma contribuição para o balanço de energia superficial em determinada área urbana. Na Tabela 1 são apresentados os mapas utilizados no caso de Belo Horizonte, como cada camada contribui para o clima urbano e que efeitos produz no balanço energético final (positivo ou negativo).

O volume edificado e as áreas não permeáveis (que também poderiam ser denominadas como "áreas impermeabilizadas") representam os termos do balanço de energia da superfície que provocam armazenamento de calor no ambiente urbano. Já as áreas verdes contribuem para a perda de calor, principalmente no período noturno. A rugosidade da superfície reduz a velocidade dos ventos, diminuindo o potencial que este termo teria em reduzir a carga térmica em escala local.

Tabela 1 - Visão geral das camadas de mapas

\begin{tabular}{|c|c|c|c|c|}
\hline Camada & Aspecto no clima urbano & $\begin{array}{l}\text { Critério Físico } \\
\text { (térmico ou dinâmico) }\end{array}$ & Dado utilizado & Classificação \\
\hline 1 - volume edificado & armazenamento de calor & $\begin{array}{l}\text { térmico } \\
\text { (efeito negativo) }\end{array}$ & $\begin{array}{l}\text { classificação da ocupação urbana, } \\
\text { incluindo número de pavimentos }\end{array}$ & $\begin{array}{l}\text { volume de edificações } \\
\left(\mathrm{m}^{3}\right)\end{array}$ \\
\hline 2 - áreas verdes & $\begin{array}{l}\text { resfriamento noturno, mitigação } \\
\text { de efeitos adversos de aumento } \\
\text { da carga térmica urbana }\end{array}$ & $\begin{array}{l}\text { térmico } \\
\text { (efeito positivo) }\end{array}$ & $\begin{array}{l}\text { classificação de áreas verdes } \\
\text { a partir de imagem de satélite } \\
\text { (resolução de } 30 \mathrm{~m} \text { ) }\end{array}$ & $\begin{array}{l}\text { presença de vegetação rasteira ou } \\
\text { vegetação arbórea } \\
\text { (m) }\end{array}$ \\
\hline 3 - declividade & $\begin{array}{l}\text { circulação local de ar induzida } \\
\text { termicamente pelo relevo }\end{array}$ & $\begin{array}{l}\text { dinâmico } \\
\text { (efeito positivo) }\end{array}$ & $\begin{array}{l}\text { modelo digital de terreno } \\
\text { (topografia) }\end{array}$ & declividade (em graus) \\
\hline 4 - áreas não permeáveis & $\begin{array}{l}\text { armazenamento de calor e } \\
\text { reductão dos fluxos de ar }\end{array}$ & $\begin{array}{l}\text { térmico e dinâmico } \\
\text { (efeito negativo) }\end{array}$ & $\begin{array}{l}\text { classificação da cobertura do solo } \\
\text { a partir de imagem de satélite } \\
\text { (resolução de } 30 \mathrm{~m} \text { ) }\end{array}$ & $\begin{array}{l}\text { existência de áreas não edificadas } \\
\text { e pavimentadas } \\
\text { (m) }\end{array}$ \\
\hline 5 - rugosidade & circulações locais de vento & $\begin{array}{l}\text { dinâmico } \\
\text { (efeito negativo) }\end{array}$ & $\begin{array}{l}\text { mapa de redução da velocidade } \\
\text { do vento diante da ocupação } \\
\text { urbana }\end{array}$ & $\begin{array}{l}\text { redução da velocidade do } \\
\text { vento }(\mathrm{m} / \mathrm{s})\end{array}$ \\
\hline
\end{tabular}

Fonte: Produzida pelos autores. 
A Figura 3 representa um fluxograma da construção e união das camadas de mapas.

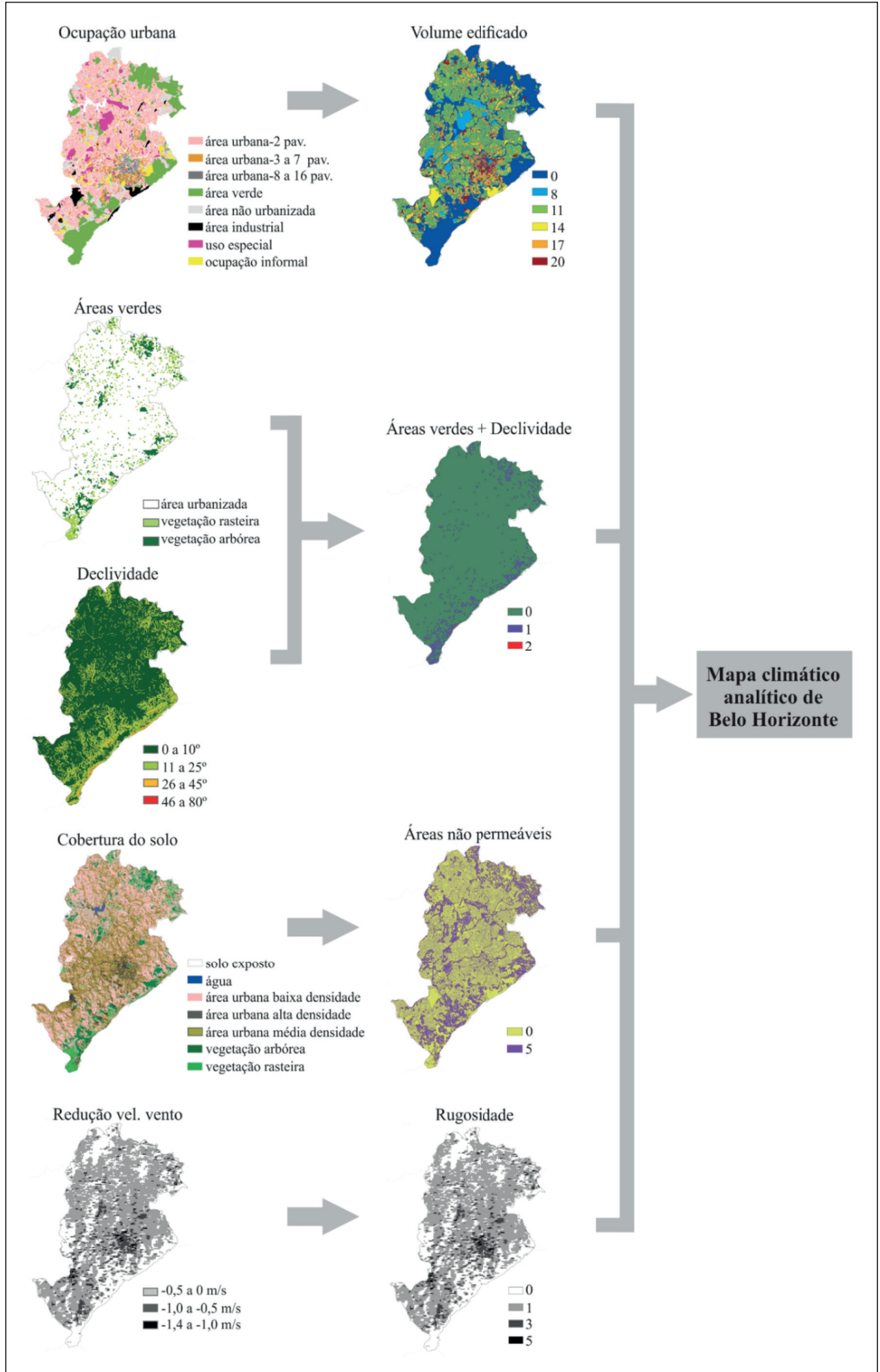

Figura 3 - Fluxograma das camadas que compõem o mapa climático de Belo Horizonte. Fonte: Produzida pelos autores. 


\section{Descrição e construção das camadas}

As cinco camadas de mapas citadas acima foram construídas a partir de mapas-base coletados em diferentes fontes documentais e tratados de forma a garantir a possibilidade de cruzamento das informações e a álgebra de mapas. Assim, os mapas foram transformados em imagens raster com resolução de $10 \mathrm{~m}$ (maior resolução dentre os mapas utilizados) e o mapa climático analítico, que exigia menor detalhamento de informações, foi produzido com resolução de $50 \mathrm{~m}$, conforme especificado abaixo.

\section{Camada 1: Volume edificado}

A camada volume edificado é uma representação do impacto do volume das construções no armazenamento de calor em ambiente urbano. As classes em que esta variável tem maior peso (ou seja, áreas representadas por números maiores), são aquelas que concentram edifícios mais altos. Em termos de resposta ao clima urbano, o efeito do adensamento urbano está relacionado predominantemente com a obstrução da visão do céu, o que retarda o resfriamento das superfícies durante as noites de céu claro e calmaria, que são as condições ideais para a formação da ilha de calor noturna (Oke, 1981).

Para a construção desta camada, utilizou-se como dado de entrada o mapa de uso do solo de Belo Horizonte, elaborado por Assis (2010) no ano de 2008. Este autor classificou o solo urbano em 11 classes, dividindo os usos em residencial e comercial (com escalas de altura de pavimentos: até 2 pavimentos, de 3 a 7 pavimentos e de 8 a 16 pavimentos), áreas verdes/parques/praças, área não urbanizada, área industrial/mineração, área de uso especial, aglomerados/vilas.

Inicialmente, estas categorias foram reclassificadas de forma a extrair classes representativas do número médio de pavimentos das edificações por quadra. Por estimativa, e tomando como referência a taxa de permeabilidade atribuída pela Lei de Uso e Ocupação do Solo de Belo Horizonte, estabeleceu-se que a ocupação média das quadras seria de $60 \%$ (áreas industriais e de uso especial), 80\% (áreas residenciais e comerciais) e
90\% (aglomerados/vilas). Assim, multiplicou-se o número de pavimentos por 3,6 metros (altura média dos andares das edificações) e, posteriormente, pela área da quadra e pela porcentagem de ocupação das quadras, obtendo-se uma estimativa do volume edificado (VE) por quadra (Equação 1). 0 volume edificado foi então reclassificado conforme apresentado na Tabela 2. Algumas correções de estimativa foram feitas por meio de análise visual dos resultados, considerando que a cidade apresenta regiões específicas com grandes quadras e baixo volume edificado, o que causou erros de cálculo deste parâmetro.

\section{$V E=$ (altura média dos edifícios) $x$ (área da quadra) $x$ (taxa de ocupação média da quadra)}

Tabela 2 - Classificação da Camada 1

\begin{tabular}{cc}
\hline Volume Edificado $\left(\mathbf{m}^{3}\right)$ & Classificação \\
\hline $0 \leq \mathrm{VE}<150$ & 0 \\
$150 \leq \mathrm{VE}<10.000$ & 8 \\
$10.000 \leq \mathrm{VE}<90.000$ & 11 \\
$90.000 \leq \mathrm{VE}<150.000$ & 14 \\
$150.000 \leq \mathrm{VE}<400.000$ & 17 \\
$400.000 \leq \mathrm{VE}<1.000 .000$ & 20 \\
$V E \geq 1.000 .000 \mathrm{e} \neq$ áreas industriais & 8 \\
áreas industriiis & 14 \\
aeroporto & 0 \\
\hline
\end{tabular}

Fonte: Produzida pelos autores.

\section{Camada 2: Áreas verdes}

A camada de áreas verdes apresenta a classificação da vegetação existente no município que poderia contribuir para a redução da carga térmica e para o resfriamento noturno. Tomou-se como base uma imagem classificada do satélite Landsat 5 (imagens TM) do ano de 2006 utilizando o método estatístico Máxima Verossimilhança (MAXVER) e o Índice de Vegetação por Diferença Normalizada (NDVI), elaborada por Ferreira (2009). A partir da imagem classificada, foram extraídas as áreas verdes do município (Tabela 3). 
Tabela 3 - Classificação da Camada 2

\begin{tabular}{cc}
\hline Presença de áreas verdes & Classificação \\
\hline não & classe 0 \\
sim & classe 1 \\
\hline
\end{tabular}

Fonte: Produzida pelos autores.

\section{Camada 3: Declividade}

A camada declividade representa uma classificação do relevo da cidade de Belo Horizonte, baseada na influência da variação topográfica nas condições de vento local. Geralmente, o ar mais frio se move para baixo ao longo dos vales, o que é benéfico para o clima local, contudo sua significância é apenas local (Lazar \& Podesser, 1999). Estes ventos se originam da produção de ar frio que é consequência do balanço negativo de radiação.

A base de informação do relevo utilizada foi o mapa topográfico da cidade de Belo Horizonte, em formato shapefile, com curvas de nível com intervalos de $20 \mathrm{~m}$, fornecido pelo Laboratório de Geoprocessamento do Instituto de Geociências da Universidade Federal de Minas Gerais (IGC/UFMG). As curvas de nível foram classificadas utilizando a ferramenta Slope do programa $\operatorname{ArcGis}^{\odot}$, o que gerou uma imagem raster com as declividades, que foram reclassificadas conforme critério da Tabela 4 .

Tabela 4 - Classificaç̃ão da Camada 3

\begin{tabular}{cc}
\hline Declividade (graus) & Classificação \\
\hline $0 \leq$ declividade $<10$ & classe 1 \\
$10 \leq$ declividade $<25$ & classe 2 \\
$25 \leq$ declividade $<45$ & classe 3 \\
declividade $\geq 45$ & classe 4 \\
\hline
\end{tabular}

Fonte: Produzida pelos autores.

Camada 2 + Camada 3:

Áreas Verdes + Declividade

A união das camadas 2 e 3 foi feita para evitar o cálculo redundante do potencial dinâmico produzido por estas variáveis. Apenas nas áreas onde existia simultaneamente vegetação e declividade superior a $10^{\circ}$ foi considerada a ocorrência do efeito dinâmico produzido pela topografia. As camadas 2 e 3 foram combinadas de forma a constituir uma única imagem com atributos que representam a união das duas camadas (Tabela 5), pois o efeito da declividade para melhoria da circulação local do ar só é considerado efetivo quando as áreas são cobertas por vegetação.

Tabela 5 - Classificação das Camadas 2 e 3 combinadas

\begin{tabular}{ccc}
\hline Declividade (graus) & Áreas verdes & Classificação \\
\hline qualquer & não & 0 \\
$0 \leq$ declividade $<10$ & sim & 0 \\
$10 \leq$ declividade $<25$ & sim & -1 \\
$25 \leq$ declividade $<45$ & sim & -1 \\
declividade $\geq 45$ & sim & -2 \\
\hline
\end{tabular}

Fonte: Produzida pelos autores.

\section{Camada 4: Áreas não permeáveis}

A camada de áreas não permeáveis avalia o efeito principalmente da pavimentação no acúmulo de calor diurno. As ruas e as áreas não edificadas cobertas por material não permeável são representadas neste mapa.

Para a definição desta camada, utilizou-se uma imagem classificada do satélite Landsat 5 (imagens TM) do ano de 2006 utilizando o método estatístico Máxima Verossimilhança (MAXVER), elaborada por Ferreira (2009). As classes atribuídas nesta classificação foram as seguintes: água, solo exposto, vegetação rasteira, vegetação arbórea, área urbana residencial, área urbana de altura média, área urbana de alta densidade.

Foi feita uma reclassificação destas categorias, considerando que as classes urbanas corresponderiam a áreas não permeáveis, enquanto que as demais (água, solo exposto, vegetação rasteira, vegetação arbórea) seriam áreas permeáveis, atribuindo, respectivamente, pesos " 5 " e " 0 ". Para não haver duplicidade de pesos para uma mesma categoria, aplicou-se uma operação de álgebra de mapas, sendo que a Camada 1 (volume edificado) foi extraída da imagem reclassificada, atribuindo novos valores às classes. Estas foram reclassificadas e considerou-se que valores menores que " 0 " corresponderiam às áreas não permeáveis, enquanto que valores maiores ou iguais a "0" seriam áreas permeáveis. Nova classificação foi feita seguindo os critérios da Tabela 6 . 
Tabela 6 - Classificação da Camada 4

\begin{tabular}{cc}
\hline Áreas não permeáveis & Classificação \\
\hline permeáveis (solo exposto, água, áreas verdes) & 0 \\
não permeáveis & 5 \\
\hline
\end{tabular}

Fonte: Produzida pelos autores.

\section{Camada 5: Rugosidade}

A rugosidade representa o quanto a ocupação do solo afeta a circulação local dos ventos. Para esta representação, utilizou-se como dado de entrada o mapa de redução da velocidade do vento considerando o efeito da ocupação urbana no ano de 2007 (Ferreira, 2009). Os dados de entrada foram obtidos a partir de simulações computacionais utilizando o software WindMap ${ }^{\mathrm{TM}}$, calibrado para dados de vento de superfície e de vento geostrófico, coletados respectivamente de estações meteorológicas fixas (2 estações localizadas no município de Belo Horizonte e 3 estações em cidades do entorno) e de sondagens do Aeroporto Internacional de Confins, situado a cerca de $40 \mathrm{~km}$ de Belo Horizonte, correspondentes ao período de 17 a 21/06/2007 (período atmosférico estável). A modelagem da região de estudo usou modelos digitais de terreno e de elevação, este último elaborado a partir da classificação de imagem do satélite Landsat do ano de 2006, em que se incorporou os valores amostrados do comprimento de rugosidade $(\mathrm{z} 0)$ para cada classe de uso do solo. Os resultados da simulação que considerou o efeito da ocupação urbana sobre o relevo foram subtraídos dos resultados da simulação em que se considerou apenas o efeito do relevo, gerando um mapa da redução da velocidade do vento no município por efeito da urbanização. A partir deste mapa, as velocidades do vento foram categorizadas e classificadas (Tabela 7), considerando que quanto maior a redução da velocidade do vento maior o efeito da rugosidade e menor o potencial dinâmico local.

Tabela 7 - Classificação da Camada 5

\begin{tabular}{cc}
\hline Redução da velocidade do vento $(\mathbf{m} / \mathbf{s})$ & Classificação \\
\hline$-1,4 \leq$ velocidade reduzida $<-1,0$ & 5 \\
$-1,0 \leq$ velocidade reduzida $<-0,5$ & 3 \\
$-0,5 \leq$ velocidade reduzida $<0$ & 1 \\
velocidade reduzida $\geq 0$ & 0 \\
\hline
\end{tabular}

Fonte: Produzida pelos autores.

\section{Mapa Climático Analítico de Belo Horizonte}

O mapa climático analítico de Belo Horizonte é o resultado da álgebra de mapas aplicada às camadas apresentadas acima, conforme a Equação 2. A imagem raster produzida desta operação foi reclassificada, resultando em oito categorias (Tabela 8).

Mapa analítico $=($ Camada 1$)-($ Camada

2 e 3$)+($ Camada 4$)+($ Camada5 $)$

Tabela 8 - Classificação do mapa climático analíitico

\begin{tabular}{cccc}
\hline $\begin{array}{c}\text { Intervalos } \\
\text { (valores calculados) }\end{array}$ & Classes & $\begin{array}{c}\text { Intervalos } \\
\text { (valores calculados) }\end{array}$ & Classes \\
\hline-2 a 5 & 1 & 18 a 19 & 5 \\
6 a 11 & 2 & 20 a 21 & 6 \\
12 a 15 & 3 & 22 a 23 & 7 \\
16 a 17 & 4 & 24 a 26 & 8 \\
\hline
\end{tabular}

Fonte: Produzida pelos autores.

\section{Resultados}

O mapa climático analítico de Belo Horizonte, conforme descrito acima, é composto por várias camadas de mapas, as quais estão representadas na Figura 3. É importante destacar alguns aspectos de cada camada que terão impacto direto na classificação dos climatopos.

Na camada volume edificado (Camada 1), verifica-se que a área central do município concentra os edifícios mais altos e com maior volume edificado e, por isso recebeu o maior peso dentre as demais categorias. As bordas da cidade, principalmente a leste, a sul/sudeste e a norte, por não apresentarem edificações, receberam valor nulo. É nestas regiões que estão concentradas as maiores áreas verdes, representadas na Camada 2 (áreas verdes): a sudeste, está o Parque Estadual da Serra do Rola Moça, em que predomina a vegetação rasteira; a leste, destacam-se o Parque Municipal das Mangabeiras e a Mata da Baleia, com maior concentração de vegetação arbórea; na extremidade norte, encontra-se a gleba denominada Granja Werneck, com áreas de vegetação rasteira e arbórea.

Quanto às declividades (Camada 3), nota-se que os maiores valores estão ao longo do limite sul do 
município, na Serra do Rola Moça, e se estende a sudeste. A maior parte do território tem declividades até $10^{\circ} \mathrm{e}$, de forma esparsa, a declividade varia entre 10 e 25‥ 0 efeito combinado da vegetação e da declividade foi considerado quando as declividades são superiores a $10^{\circ}$, o que poderia potencializar a ocorrência do efeito dinâmico produzido pela topografia. Observa-se que este efeito é bastante esparso na cidade e mais uma vez há maior concentração ao sul, leste e extremo norte. 0 efeito combinado das duas variáveis praticamente não é visível na área central do município.

No que se refere à rugosidade (Camada 5), é possível verificar que a área central da cidade, que corresponde à ocupação mais densa e com edificações mais altas, é a que mais sofre com este efeito negativo. Na maior parte do território, por sua vez, a redução da velocidade dos ventos é da ordem de até $0,5 \mathrm{~m} / \mathrm{s}$, o que tem pouca relevância quanto ao impacto no clima urbano.
A partir da constatação da contribuição das diversas camadas de mapas para o balanço de energia urbano, construiu-se o mapa climático analítico para Belo Horizonte, apresentado na Figura 4 e na Tabela 9. Os efeitos positivos e negativos produzidos pela carga térmica do ambiente urbano e o potencial dinâmico local foram categorizadas em oito classes climáticas urbanas, as quais representam os climatopos.

A Classe 1 representa áreas em que o efeito da carga térmica é moderadamente negativo, pois está associado a maiores altitudes e, consequentemente, ao resfriamento adiabático proporcionado por estas áreas adicionado à presença de vegetação, o que provoca resfriamento evaporativo. Na Classe 2, a carga térmica é ligeiramente negativa e o potencial dinâmico ainda se mantém positivo. As Classes 3 a 8 , por sua vez, apresentam impacto ao clima local relacionado ao aquecimento devido ao aumento da carga térmica e à redução do potencial dinâmico.

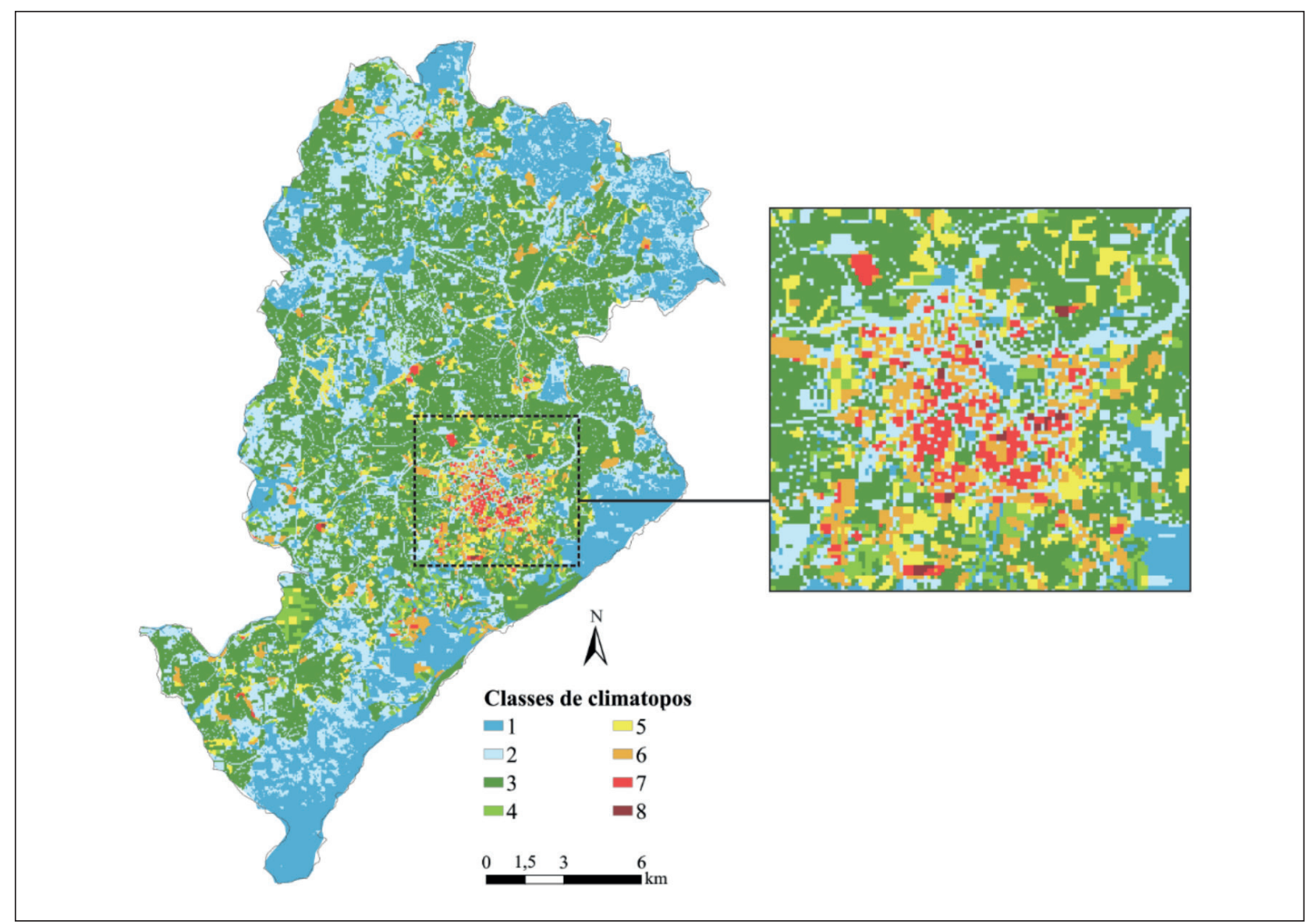

Figura 4 - Mapa climático analítico de Belo Horizonte. (A área ampliada corresponde à área central da cidade). Fonte: Produzida pelos autores. 
Tabela 9 - Classes de climatopos

\begin{tabular}{cc}
\hline Climatopo & Classe climática urbana \\
\hline 1 & Carga térmica moderadamente negativa e bom potencial dinâmico \\
2 & Carga térmica ligeiramente negativa e bom potencial dinâmico \\
3 & Baixa carga térmica e bom potencial dinâmico \\
4 & Alguma carga térmica e algum potencial dinâmico \\
5 & Carga térmica moderada e algum potencial dinâmico \\
6 & Carga térmica moderadamente alta e baixo potencial dinâmico \\
7 & Carga térmica alta e baixo potencial dinâmico \\
8 & Carga térmica muito alta e baixo potencial dinâmico \\
\hline
\end{tabular}

Fonte: Produzida pelos autores.

Verifica-se que os limites do município ao sul, sudeste e nordeste, que concentram as maiores extensões de áreas verdes, têm maior potencial dinâmico e menor carga térmica, o que favorece o resfriamento noturno e as condições de conforto higrotérmico humano. As áreas densamente ocupadas por edificações, que correspondem ao centro da cidade (ver detalhe ampliado da Figura 4), por sua vez, têm baixa capacidade de resfriamento noturno, pois a carga térmica acumulada e o baixo potencial dinâmico favorecem o aquecimento das superfícies, o que pode levar a condições de maior desconforto humano.

A Figura 5 apresenta a distribuição das classes de climatopos em Belo Horizonte. É possível observar que praticamente metade do território da cidade é representado pelas classes de climatopo 1 e 2, que têm como resposta atmosférica carga térmica negativa e bom potencial dinâmico. A classe de maior representatividade no município é a 3, em que os efeitos da carga térmica ainda são baixos e preserva-se bom potencial dinâmico. As classes de maior impacto quanto a carga térmica e potencial dinâmico representam cerca de 10\% da área da cidade.

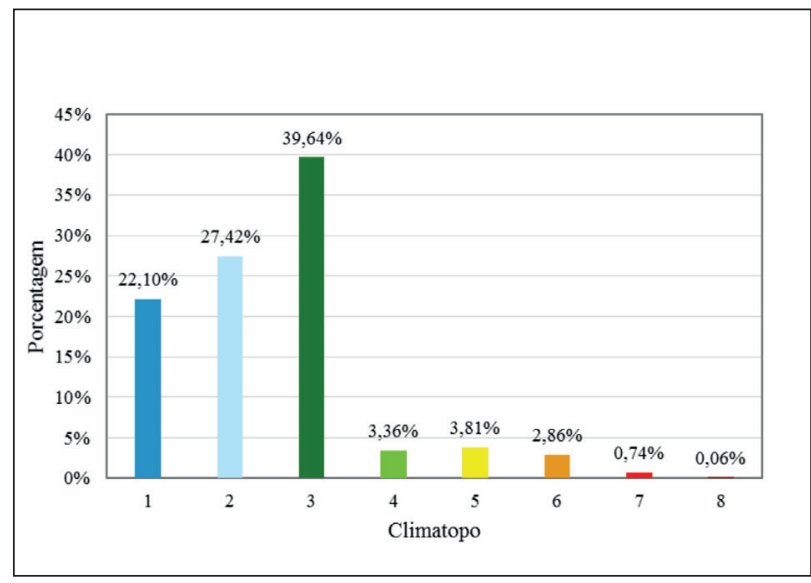

FIGURA 5 - Gráfico de distribuição das classes de climatopos em Belo Horizonte.

Fonte: Produzida pelos autores.

Nota-se, então, que na maior parte do território belo-horizontino o impacto negativo dos elementos urbanos no balanço de energia da superfície mostrou-se nulo ou baixo. Uma das explicações para este resultado é que a forma de urbanização da cidade levou à concentração de áreas densamente ocupadas por edificações na região central do município (basicamente, dentro do anel formado pela avenida do Contorno e suas imediações), enquanto que no entorno da área central há, ainda, o predomínio de edificações de baixa volumetria (o detalhe ampliado da Figura 4 mostra esta área). Como aqui se considerou que o volume edificado seria o termo de maior contribuição para o ganho de carga térmica no balanço de energia da superfície, o adensamento construtivo é um aspecto relevante na definição das classes climáticas.

Contudo, outro aspecto que deve ser avaliado concomitantemente é a contribuição dos elementos urbanos na minimização do pontecial dinâmico, termo de perda de carga térmica no balanço energético. No caso de Belo Horizonte, esta variável precisa ser vista com cautela. Conforme já apontado por Ferreira (2009) e Ferreira \& Assis (2015), como a velocidade dos ventos na cidade é naturalmente baixa, a alteração da cobertura do solo e o consequente aumento da sua rugosidade causa redução da magnitude do vento, o que pode trazer consequências ambientais severas com a diminuição do potencial dinâmico ainda existente. Assim, considera-se relevante que se avaliem as formas de adensamento de novas áreas do tecido 
urbano, para que estas não comprometam ainda mais a ventilação na cidade, principalmente em áreas que naturalmente apresentam baixas velocidades de vento.

Uma consideração importante neste estudo é sobre a base de dados que deu origem ao mapa climático. Os mapas de volume edificado, áreas verdes e rugosidade foram produzidos a partir de informações dos anos de 2006 a 2008, ou seja, há uma defasagem dos dados de quase dez anos, o que é uma limitação deste estudo. Como são dados que podem sofrer alteração significativa ao longo do tempo, é preciso que sejam atualizados constantemente para garantir uma melhor representação da realidade e, assim, sejam de fato úteis ao planejamento.

\section{Considerações finais}

Os mapas climáticos são instrumentos utilizados como suporte ao planejamento urbano atualmente em várias cidades no mundo. Uma das vantagens do uso desta metodologia é a sua abordagem multidisciplinar, que agrega conhecimentos da climatologia e do planejamento urbano em um sistema de informação geográfica cuja linguagem é facilmente entendida pelos planejadores (Ren et al., 2011). Contudo, a construção e integração das informações dependem da avaliação de dados qualitativos e quantitativos que demandam a experiência local dos climatologistas e dos planejadores urbanos, o que pode ser uma limitação para a sua aplicação.

No Brasil, os estudos ainda são incipientes, porém observa-se que o uso de métodos geográficos leva à necessidade de interpretação e, eventualmente, de adaptação dos procedimentos originais, de acordo com as informações disponíveis localmente e com a observação prévia das realidades locais. Esta interpretação é importante para o estabelecimento de pesos viáveis para as variáveis.

Apesar de certo grau de subjetividade na classificação das variáveis, os mapas temáticos têm a vantagem de poder ser atualizados com relativa rapidez, bem como o procedimento para a geração de cada um deles pode ser aperfeiçoado. Um desafio é integrar a informação em todos os níveis, de modo a servir tanto à escala de planejamento urbano quanto à escala de desenho urbano.

Ressalte-se a importância para Belo Horizonte, de acordo com os resultados obtidos, da preservação das áreas verdes e das classes de climatopos 1 e 2, onde as condições ambientais são mais favoráveis ao conforto higrotérmico humano. Por serem áreas de ocupação urbana baixa ou praticamente nula, o efeito da urbanização no clima pode ser menor. Estas áreas se mostram essenciais para auxiliar na promoção do resfriamento noturno da cidade e, no caso do limite sudeste do município, ainda é considerada a entrada de ventos da cidade (Ferreira, 2009).

As áreas de climatopos 7 e 8, as quais se concentram no centro da cidade, parecem ser as mais sensíveis quanto a mudanças na ocupação do solo, pois são densamente ocupadas e verticalizadas, têm baixas velocidades de vento (Ferreira \& Assis, 2015) e as condições associadas ao clima tendem, portanto, a levar ao desconforto humano. Como, nestas áreas, a legislação urbanística permite maior adensamento urbano e maior verticalização, o risco de comprometimento ainda maior das condições climáticas e de conforto térmico é grande, visto que um maior adensamento construtivo poderia incorrer no incremento da carga térmica e na menor possibilidade de resfriamento noturno.

A partir destes resultados, pretende-se desenvolver um mapa com recomendações para o planejamento urbano de Belo Horizonte, a fim de apresentar estratégias que possam mitigar o impacto da urbanização na alteração do clima local e melhorar o conforto humano nas áreas urbanas. Desta forma, poder-se-ia contribuir para a gestão urbana, incorporando informações climáticas ao planejamento, o que é uma ferramenta para a compreensão da relação da cidade com as mudanças climáticas - um tema que se insere como um dos desafios da Nova Agenda Urbana proposta pela Organização das Nações Unidas.

\section{Agradecimentos}

Os autores agradecem à Fundação de Amparo à Pesquisa do Estado de Minas Gerais (FAPEMIG) pelo apoio ao projeto de pesquisa APQ-00146-12, 
através do qual foi concedida, à Arq. M.Sc. Daniele G. Ferreira, a bolsa de Incentivo à Pesquisa e ao Desenvolvimento Tecnológico, destinada a Servidor Público Estadual (BIP-00286-15), e a bolsa de Especialista Visitante, BPV-00052-13, em cooperação com o DAAD, ao Prof. Dr. Lutz Katzschner. Agradecem também ao Prof. Dr. Wellington Lopes Assis pela cessão de mapas produzidos em seu doutoramento e ao Instituto de Geociências da Universidade Federal de Minas Gerais (IGC/UFMG), pelo fornecimento de mapa-base municipal.

\section{Referências}

Alcoforado, M. J., Lopes, A., Andrade, H., \& Vasconcelos, J. (2006). Orientações climáticas para o ordenamento em Lisboa. Centro de Estudos Geográficos da Universidade de Lisboa, Lisboa.

Amaral, F. M. P. (s/d). O conceito de Unidades de Planejamento (UPs) em Belo Horizonte. Espaço de encontro entre planejamento e orçamento participativo. Apresentação da Prefeitura de Belo Horizonte. Recuperado em janeiro de 2016, de http://slideplayer. com.br/slide/1257388/

Assis, E. S. (1995). O plano de Belo Horizonte em fins do século XIX: o enunciado e o visível. Os Processos de Planejamento e Projeto Urbano (Monografia para a disciplina AUT800). Faculdade de Arquitetura e Urbanismo, Universidade de São Paulo, São Paulo.

Assis, E. S. (2005). A abordagem do clima urbano e aplicações no planejamento da cidade: reflexões sobre uma trajetória. In Anais do $8^{o}$ Encontro Nacional sobre Conforto no Ambiente Construído (p. 92-101). Maceió: ENCAC.

Assis, W. L. (2010). O sistema clima urbano do município de Belo Horizonte na perspectiva têmporo-espacial (Tese Doutorado em Geografia). Instituto de Geociências, Universidade Federal de Minas Gerais, Belo Horizonte.

Assis, W. L., \& Abreu, M. L. (2009). Mudanças climáticas locais no município de Belo Horizonte ao longo do século XX. In D. J. Hogan, \& E. Marandola Jr. (Org.), População e mudança climática: dimensões humanas das mudanças ambientais globais (p. 249-275). Brasília: NEPO-Unicamp, Campinas \& UNFPA.
Aylett, A. (2015). Institutionalizing the urban governance of climate change adaptation: results of an international survey. Urban Climate, 14, 4-16.

Baden-Württemberg Innenministerium (2004). Climate booklet for urban development, Ministry of Economy Baden-Württemberg; Environmental Protection Department of Stuttgart, Stuttgart. Recuperado em janeiro de 2016, de http://www.staedtebauliche-klimafibel.

Belo Horizonte (1976, 29 de novembro). Lei n. 2.662, de 29 de novembro de 1976. Dispõe sobre normas de uso e ocupação do solo no município de Belo Horizonte, e dá outras providências. Belo Horizonte: Diário Oficial do Município.

Belo Horizonte (1996, 27 de agosto). Lei n. 7.166, de 27 de agosto de 1996. Estabelece normas e condições para parcelamento, ocupação e uso do solo urbano no município. Belo Horizonte: Diário Oficial do Município.

Belo Horizonte (2010, 20 de julho). Lei 9.959, de 20 de julho de 2010. Altera as leis n. 7.165/96 - que institui o Plano Diretor do Município de Belo Horizonte - e n. 7.166/96 - que estabelece normas e condições para parcelamento, ocupação e uso do solo urbano no Município -, estabelece normas e condições para a urbanização e a regularização fundiária das Zonas de Especial Interesse Social, dispõe sobre parcelamento, ocupação e uso do solo nas Áreas de Especial Interesse Social, e dá outras providências. Belo Horizonte: Diário Oficial do Município.

Ferreira, D. G. (2009). O uso do solo e os padrões de vento: o caso da cidade de Belo Horizonte. (Dissertação Mestrado Interdisciplinar em Ambiente Construído e Patrimônio Sustentável). Escola de Arquitetura, Universidade Federal de Minas Gerais, Belo Horizonte.

Ferreira, D. G. \& Assis, E. S. (2015). Simulações de vento e sua aplicação no planejamento urbano. UR Cadernos da Faculdade de Arquitetura da Universidade de Lisboa, 8, 6-15.

Instituto Nacional de Meteorologia - INMET (2009). Normas Climatológicas do Brasil 1961-1990. Brasília.

Katzschner, L. (2005). The contribution of urban climate studies to a new urbanity. In Anais do $8^{\circ}$ Encontro Nacional sobre Conforto no Ambiente Construído (p. 912920). Maceió: ENCAC. 
Katzschner, L., \& Mülder, J. (2008). Regional climatic mapping as a tool for sustainable development. Journal of Environmental Management, 87, 262-267.

Lazar, R., \& Podesser, A. (1999). An urban climate analysis of Graz and its significance for urban planning in the tributary valleys east of Graz (Austria). Atmospheric Environment, 33, 4195-4209.

Mills, G. (2015). Chapter 1: Introduction. In Ng, E. e Ren, C. (Editors). The Urban Climatic Map: A Methodology for

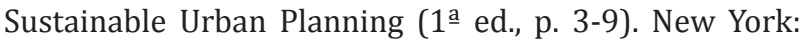
Taylor \& Francis Group.

Monteiro, C. A. F. (1976). Teoria e clima urbano (Tese Livre Docência). Faculdade de Filosofia, Letras e Ciências Humanas, Universidade de São Paulo, São Paulo.

Monteiro, C. A. F. (1986). Some aspects of the urban climate of tropical South America: the Brazilian contribution. In Proceedings of the Technical Conference on Urban Climatology and Its Applications with Special Regard to Tropical Areas (p. 166-197). Mexico City: WMO N. 652.

Moura, A. C. M., Jankowski, P. L., \& Cocco, C. (2014). Contribuições aos estudos de análises de incertezas como complementação às análises multicritérios - Sensitivity Analysis to Suitability Evaluation, Anais do XXVI Congresso Brasileiro de Cartografia, (p. 1-20). Gramado.

Nery, J., Freire, T., Andrade, T., \& Katzschner, L. (2006). Thermal comfort studies in a humid tropical city. In Preprints of the $6^{\text {th }}$ International Conference on Urban Climate (p. 234-237). Göteborg: ICUC.

Oke, T. R. (1981). Canyon geometry and the nocturnal heat island: Comparison of scale model and field observations, Journal of Climatology, 1, 237-254.

Oke, T. R. (1984). Towards a prescription of the greater use of climatic principles in settlement planning, Energy and Buildings, 7, 1-10.
Planning Department of Hong Kong (2006). Urban climatic map and standards for wind environment - Feasibility Study: Final Report, ARUP; The Hong Kong University of Science and Technology; PlanArch Consultants Ltd.; Universitat Kassel, Hong Kong. Recuperado em abri de 2015, de http://www.pland.gov.hk/pland_en/p_study/ prog_s/ucmapweb/ucmap_project/content/reports/final_report.pdf

Prata-Shimomura, A. R., Lopes, A. S., \& Correia, E. (2015). Urban Climatic Map Studies in Brazil: Campinas. In: Ng, E. e Ren, C. (Eds.). The Urban Climatic Map: A Methodology for Sustainable Urban Planning (1 ${ }^{\text {a }}$ ed., p. 237-246). New York: Taylor \& Francis Group.

Ren, C., Ng, E. \& Katzschner, L. (2011). Urban climatic map studies: a review. International Journal of Climatology, 31, 2213-2233.

Scherer, D., Fehrenbach, U., \& Parlow, E. (1999). Improved concepts and methods in analysis and evaluation of the urban climate for optimizing urban planning processes. Atmospheric Environment, 33, 4185-4193.

Souza, V. S. (2010). Mapa climático urbano da cidade de João Pessoa - PB, João Pessoa (Dissertação Mestrado em Arquitetura e Urbanismo). Universidade Federal da Paraíba, João Pessoa.

Taesler, R. (1986). Urban climatological methods and data. In Proceedings of the Technical Conference on Urban Climatology and Its Applications with Special Regard to Tropical Areas (p. 166-197). Mexico City: WMO N. 652.

Verein Deutscher Ingenieure - VDI (1997). VDI-Guideline 3787, Part 1: Environmental Meteorology - Climate and Air Pollution Maps for Cities and Regions. Berlin: VDI, Beuth Verlag.
Recebido: Nov. 15, 2016

Aprovado: Mar. 06, 2017 